\title{
Influence of Coadministered Antiepileptic Drugs on Serum Zonisamide Concentrations in Epileptic Patients: Quantitative Analysis Based on Suitable Transforming Factor
}

\author{
Noriyasu Fukuoka, ${ }^{*, a}$ Toyohisa Tsukamoto, ${ }^{a}$ Junji Uno, ${ }^{b}$ Michio Kimura, ${ }^{c}$ and Shushi Morita ${ }^{a}$ \\ ${ }^{a}$ Department of Hospital Pharmacy, Kagawa Medical University; 1750-1 Ikenobe, Miki-cho, Kita-gun, Kagawa \\ 761-0793, Japan: ${ }^{b}$ Department of Hospital Pharmacy, Okehazama Hospital; 3-879 Minamiyakata, Sakae-machi, \\ Toyoake, Aichi 470-1168, Japan: and ${ }^{c}$ Pharmaceutical Division, Kurashiki Central Hospital; 1-1-1 Miwa, Kurashiki, \\ Okayama 710-8602, Japan. Received April 23, 2003; accepted October 2, 2003
}

\begin{abstract}
We conducted a study to clarify the most suitable transforming factor related to the daily zonisamide dose $(D)$ providing a steady-state serum concentration $\left(C_{t}\right)$ and analyzed the influences of the concomitant use of antiepileptic drugs on $C_{\mathrm{t}}$ quantitatively. Data obtained by routine therapeutic drug monitoring from a total of 175 epileptic patients treated with the multiple oral administrations of zonisamide (ZNS) as a powder/tablets, were used for the analysis. Employing the extracellular water volume $\left(V_{E C W}\right)$ as a transforming factor, led the level/dose (L/D) ratio (: $\left.C_{\mathrm{t}} /\left(D / V_{\mathrm{ECW}}\right)\right)$ to be independent of the patient's age and sex for the administration of ZNS alone. $C_{\mathrm{t}}$ was revealed to be dependent on only one variable regarding $D / V_{\mathrm{ECW}}$ and expressed as $C_{\mathrm{t}}=0.604 \times\left(D / V_{\mathrm{ECW}}\right)$. Phenytoin (PHT) significantly lowered $(p<0.01)$ the $\mathrm{L} / \mathrm{D}$ ratio to 0.76 of the value for ZNS alone. For a more detailed analysis, we defined the parameter $R_{i}(i=1,2, \ldots, 6)$ as an alteration ratio, representing the influence of each antiepileptic drug on the L/D ratio of ZNS alone. A model based on the assumption that each $R_{i}$ value was independent from one another and multiplicative, was adopted. The analysis clarified that phenobarbital, valproic acid, carbamazepine, and PHT significantly lowered $(p<0.05)$ the $\mathrm{L} / \mathrm{D}$ ratio of ZNS to 0.849 , $0.865,0.846$, and 0.804 , respectively. In the case of the addition or discontinuance of concomitant treatment with antiepileptic drugs in the same patient, the estimated $L / D$ ratios were calculated using the value of each $R_{i}$ and compared with the measured ones. The mean of prediction error was calculated as $22.9 \%$. Our results appear valid and $R_{i}$ should be available for clinical use.
\end{abstract}

Key words zonisamide; transforming factor; level/dose ratio; extracellular water volume; concomitant therapy; alteration ratio

Zonisamide (ZNS) is frequently added on conventional epileptic therapy for refractory seizures. ${ }^{1)}$ It is clinically important to clarify the influences of antiepileptic drugs on the serum ZNS concentration in a steady-state $\left(C_{t}\right)$.

Before investigating the influences on $C_{\mathrm{t}}$, it is preferable to clarify the relation between daily dose $(D)$ and $C_{\mathrm{t}}$ in the administration of ZNS alone. $C_{\mathrm{t}}$ and $D$ are expressed as a function of clearance. Body weight $(W)$ or body surface area, corresponding to clearance, has been used as a substitute for clearance (transforming factor). $D$ is transformed to a variable (transformed daily dose: $D^{\prime}$ ) being divided by a transforming factor, $C_{\mathrm{t}}$ is thus related to $D^{\prime}$.

The influences of antiepileptic drugs on $C_{\mathrm{t}} / D^{\prime}$ (level/dose (L/D) ratio) have been examined, but no regard has been paid to the influences of confounding factors such as age and sex. Employing $W$ as a transforming factor, the $\mathrm{L} / \mathrm{D}$ ratio $\left(C_{\mathrm{t}} /(D / W): C_{\mathrm{t}} / D_{\mathrm{W}}^{\prime}\right)$ was found to be dependent on age. ${ }^{2)}$ The analyses based on $C_{\mathrm{t}} / D_{\mathrm{W}}^{\prime}$ were misleading because the patients might be grouped by age. ${ }^{3)}$ If $D^{\prime}$, which was related to $C_{\mathrm{t}}$ without being affected by confounding factors, could be determined, it would be worth evaluating for clinical use.

The authors showed that ideal body weight or extracellular water volume $\left(V_{\mathrm{ECW}}\right)$ could be used as a transforming factor to relate the serum concentration with the daily dose without an effect by confounding factors for valproic acid (VPA $)^{4)}$ or carbamazepine (CBZ), ${ }^{5)}$ respectively. The influences of concomitant drug use on the serum concentration were evaluated quantitatively in all the patients without them being grouped by other confounding factors. ${ }^{6,7)}$

In this paper, $V_{\mathrm{ECW}}$ also affected the L/D ratio of ZNS independent of confounding factors. Then the authors detected the drug affecting the $\mathrm{L} / \mathrm{D}$ ratio and investigated its influence quantitatively.

\section{METHODS}

We collected data from epileptic patients, who were chronically treated with multiple oral administrations of ZNS (Excegran $^{\circledR}$ granules/tablets, Dainippon Pharmaceutical Co., Osaka, Japan) at Kagawa Medical University Hospital between April 1995 and May 1998 and at Kurashiki Central Hospital between April and September 1996. The total number of patients administered ZNS was 175 . Patients with abnormal findings on hepatic and renal function tests were excluded. Blood samples were drawn 2 to $3 \mathrm{~h}$ after the last dosing in outpatients and 2 to $15 \mathrm{~h}$ in inpatients. The fluctuations of $C_{\mathrm{t}}$ at different sampling times were considered to be negligible because of its long elimination half-life. ${ }^{8)}$

When there were multiple measurements for $C_{\mathrm{t}}$ in one patient with the same prescribed drugs during the study period, the average value was used. The age, body weight, height and daily ZNS dose were treated in the same manner. When several varieties of drugs were prescribed in one patient, the count was taken as the number of patients. In both hospitals, $C_{\mathrm{t}}$ was measured in duplicate by HPLC and the average value employed.

Data analysis was performed by utilizing a statistical package, NAP (ver.4). ${ }^{9}$

\section{RESULTS}

Patient Characteristics Table 1 shows the characteris- 


\begin{tabular}{|c|c|c|c|c|c|}
\hline & \multicolumn{3}{|c|}{ Total or mean \pm S.D. } & \multirow{2}{*}{$t$ or $\chi^{2}$ test } \\
\hline & & $\begin{array}{l}\text { Kagawa Medical } \\
\text { University Hospital }\end{array}$ & $\begin{array}{c}\text { Kurashiki Central } \\
\text { Hospital }\end{array}$ & Both Hospitals & \\
\hline \multicolumn{2}{|l|}{ Total no. of patients } & 81 & 94 & 175 & \multirow{2}{*}{$\overline{\mathrm{NS}}$} \\
\hline \multicolumn{2}{|c|}{$\begin{array}{ll}\text { Sex: SEX } & \text { Male } \\
& \text { Female }\end{array}$} & $\begin{array}{l}39 \\
42\end{array}$ & $\begin{array}{l}56 \\
38\end{array}$ & $\begin{array}{l}95 \\
80\end{array}$ & \\
\hline \multicolumn{2}{|l|}{ Age: $A G E$ [years] } & $42.7 \pm 22.8$ & $43.2 \pm 20.9$ & $43.0 \pm 21.7(1-86)$ & NS \\
\hline \multicolumn{2}{|c|}{ Body weight: $W[\mathrm{~kg}]$} & $54.4 \pm 16.8$ & $52.8 \pm 14.6$ & $53.6 \pm 15.6(6.7-94.0)$ & NS \\
\hline \multicolumn{2}{|l|}{ Height: $H[\mathrm{~cm}]$} & $154.4 \pm 18.2$ & $155.9 \pm 21.1$ & $155.2 \pm 19.7(69-187)$ & NS \\
\hline \multicolumn{2}{|c|}{ Daily ZNS dose: $D[\mathrm{mg} / \mathrm{d}]$} & $278.3 \pm 98.5$ & $243.2 \pm 115.4$ & $259.4 \pm 109.0(35-600)$ & $p<0.05$ \\
\hline \multicolumn{2}{|c|}{ Serum ZNS concentration: $C_{\mathrm{t}}[\mu \mathrm{g} / \mathrm{ml}]$} & $17.4 \pm 8.0$ & $15.6 \pm 7.3$ & $16.4 \pm 7.7(3.6-43.3)$ & NS \\
\hline ZNS therapy & $\begin{array}{c}\text { Alone } \\
\text { Concomitant }\end{array}$ & $\begin{array}{l}20 \\
61\end{array}$ & $\begin{array}{l}37 \\
57\end{array}$ & $\begin{array}{r}57 \\
118\end{array}$ & NS \\
\hline No. of drugs & 1 & 32 & 43 & 75 & \multirow[b]{2}{*}{$p<0.05$} \\
\hline Coadministered & $\begin{array}{r}2 \\
3 \\
>4\end{array}$ & $\begin{array}{r}24 \\
4 \\
1\end{array}$ & $\begin{array}{l}9 \\
3 \\
2\end{array}$ & $\begin{array}{r}33 \\
7 \\
3\end{array}$ & \\
\hline
\end{tabular}

$t, \chi^{2}$ test: comparison between both hospitals. Values in parentheses indicate the range. NS: not significant.

Table 2. Sex and Age Differences in the L/D Ratio for Each Transforming Factor

\begin{tabular}{|c|c|c|c|c|c|}
\hline & $\begin{array}{r}\text { Transforming factor } \\
\text { L/D ratio }\end{array}$ & $\begin{array}{c}W \\
C_{\mathrm{t}} / D_{\mathrm{W}}^{\prime}\end{array}$ & $\begin{array}{l}V_{\mathrm{TBW}} \\
C_{\mathrm{t}} / D_{\mathrm{TBW}}^{\prime}\end{array}$ & $\begin{array}{l}B S A \\
C_{\mathrm{t}} / D_{\mathrm{BSA}}^{\prime}\end{array}$ & $\begin{array}{l}V_{\mathrm{ECW}} \\
C_{\mathrm{t}} / D_{\mathrm{ECW}}^{\prime}\end{array}$ \\
\hline Sex & $\begin{array}{l}\text { Male (27) } \\
\text { Female (30) }\end{array}$ & $\left.\begin{array}{l}4.23 \pm 1.29 \\
3.65 \pm 1.47\end{array}\right] \mathrm{NS}$ & $\left.\begin{array}{l}2.26 \pm 0.63 \\
1.95 \pm 0.75\end{array}\right] \mathrm{NS}$ & $\left.\begin{array}{l}0.12 \pm 0.03 \\
0.11 \pm 0.04\end{array}\right] \mathrm{NS}$ & $\left.\begin{array}{l}0.65 \pm 0.16 \\
0.57 \pm 0.21\end{array}\right] \mathrm{NS}$ \\
\hline Age & $\begin{array}{l}<15(6) \\
\geqq 15(51)\end{array}$ & $\left.\begin{array}{l}2.34 \pm 0.73 \\
4.11 \pm 1.35\end{array}\right] * *$ & $\left.\begin{array}{l}1.43 \pm 0.47 \\
2.18 \pm 0.69\end{array}\right] *$ & $\left.\begin{array}{l}0.09 \pm 0.03 \\
0.12 \pm 0.04\end{array}\right] \mathrm{NS}$ & $\left.\begin{array}{l}0.51 \pm 0.16 \\
0.62 \pm 0.19\end{array}\right] \mathrm{NS}$ \\
\hline
\end{tabular}

NS: Not significant. $* * p<0.01, * p<0.05$. ( ): number of patients.

tics of the patients administered ZNS in each hospital. We combined the data from the two hospitals to elevate the power of tests in the analysis and to obtain various combinations of concomitant therapy.

\section{ZNS Alone}

Correlation of L/D Ratio with Sex and Age As shown in Table 2, four types of transforming factor corresponding to clearance, i.e., $W$, total body water volume $\left(V_{\mathrm{TBW}}\right)$, body surface area $(B S A)$ and $V_{\mathrm{ECW}}$, were used to detect the correlation of $\mathrm{L} / \mathrm{D}$ ratio with sex and age. The following transformed daily doses, $D_{\mathrm{W}}^{\prime}(=D / W), D_{\mathrm{TBW}}^{\prime}\left(=D / V_{\mathrm{TBW}}\right)$, $D_{\mathrm{BSA}}^{\prime}(=D / B S A)$, and $D_{\mathrm{ECW}}^{\prime}\left(=D / V_{\mathrm{ECW}}\right)$, were proposed.

Empirical formulas (1), (2), and (3) have been reported for $V_{\mathrm{TBW}}{ }^{10)} B S A,{ }^{11)}$ and $V_{\mathrm{ECW}},{ }^{10)}$ respectively.

$$
\begin{aligned}
& V_{\mathrm{TBW}}[1]=0.135 \times W^{0.666} \times H^{0.535} \\
& B S A\left[\mathrm{~m}^{2}\right]=0.007246 \times W^{0.425} \times H^{0.725} \\
& V_{\mathrm{ECW}}[1]=0.068 \times W^{0.400} \times H^{0.633} \\
& \quad(W \text { : body weight }[\mathrm{kg}], H \text { : height }[\mathrm{cm}])
\end{aligned}
$$

The correlation of age with the $\mathrm{L} / \mathrm{D}$ ratio was investigated for two groups, age $<15$ and age $\geqq 15$. $C_{\mathrm{t}} / D_{\mathrm{W}}^{\prime}$ and $C_{\mathrm{t}} /$ $D_{\text {TBW }}^{\prime}$ showed a significant difference between the two groups, but $C_{\mathrm{t}} / D_{\mathrm{BSA}}^{\prime}$ and $C_{\mathrm{t}} / D_{\mathrm{ECW}}^{\prime}$ did not. In contrast, the $\mathrm{L} / \mathrm{D}$ ratios showed no significant difference between sex.

Factors Influencing $\boldsymbol{C}_{\mathrm{t}}$ The data from the 175 patients were used for multiple regression analysis, with $C_{\mathrm{t}}$ assigned as the criterion variable and $D_{\mathrm{W}}^{\prime}, D_{\mathrm{TBW}}^{\prime}, D_{\mathrm{BSA}}^{\prime}$, or $D_{\mathrm{ECW}}^{\prime}$ as the main-explanatory variable. $W, D$, age $(A G E)$, and sex $(S E X)$ were assigned as the sub-explanatory variables. The forward selection method was used to select the variables influencing $C_{\mathrm{t}}$. The level of significance, which prescribed the addition and/or elimination of a variable using the $F$-test, was taken as 0.05 .

In Table 3, the standard partial regression coefficients of the selected explanatory variables, namely the factors influencing $C_{\mathrm{t}}$, the simple correlation coefficient $\left(r_{\mathrm{s}}\right)$ between the main-explanatory variable and $C_{\mathrm{t}}$, and the multiple correlation coefficient $\left(r_{\mathrm{m}}\right)$ between all selected explanatory variables and $C_{\mathrm{t}}$ are shown. In the case of $D_{\mathrm{W}}^{\prime}$ or $D_{\mathrm{TBW}}^{\prime}, D^{\prime}$ or $A G E$ was selected as the sub-explanatory variable, respectively. The difference between $r_{\mathrm{m}}{ }^{2}$ and $r_{\mathrm{s}}{ }^{2}$ indicates the contribution of the sub-explanatory variable to $C_{\mathrm{t}}$. In contrast, only the main-explanatory variable was selected in the cases of $D_{\mathrm{BSA}}^{\prime}$ and $D_{\mathrm{ECW}}^{\prime}$. That is, $C_{\mathrm{t}}$ could be related only with the variable $D_{\mathrm{BSA}}^{\prime}$ or $D_{\mathrm{ECW}}^{\prime}$.

The relationship between $C_{\mathrm{t}}$ and $D_{\mathrm{ECW}}^{\prime}$ showed a better correlation than that obtained from the other $D^{\prime}$ values and $C_{\mathrm{t}}$ could be expressed approximately as a function of $D_{\mathrm{ECW}}^{\prime}$ as $C_{\mathrm{t}}=0.604 \times D_{\mathrm{ECW}}^{\prime}$ (Fig. 1; line 1).

\section{Concomitant Therapy}

Influence of One Drug on $\boldsymbol{C}_{\mathrm{t}}$ It is comprehensible to investigate the influence of concomitant drug use by first examining the effect of one drug. Seventy-five patients were coadministered one antiepileptic drug such as phenobarbital (PB), VPA, CBZ, or phenytoin (PHT) (Table 4). For $\mathrm{ZNS}+\mathrm{PHT}$, the correlation of $C_{\mathrm{t}}$ versus $D_{\mathrm{ECW}}^{\prime}$ was approxi- 
Table 3. Standard Partial Regression Coefficients of Selected Explanatory Variables and Correlation Coefficients Calculated by Multiple Regression Analysis

\begin{tabular}{|c|c|c|c|c|c|}
\hline \multicolumn{2}{|c|}{ Transforming factor } & \multirow{2}{*}{$\begin{array}{c}W \\
0.353\end{array}$} & \multirow{2}{*}{$\begin{array}{l}V_{\mathrm{TBW}} \\
0.710\end{array}$} & \multirow{2}{*}{$\begin{array}{c}B S A \\
0.743\end{array}$} & \multirow{2}{*}{$\begin{array}{l}V_{\mathrm{ECW}} \\
0.745\end{array}$} \\
\hline Main-explanatory variable & Transformed daily dose: $D^{\prime}$ & & & & \\
\hline Sub-explanatory variable & Sex: $S E X$ & NS & NS & NS & NS \\
\hline & Age: $A G E$ & NS & 0.214 & NS & NS \\
\hline & Body weight: $W$ & NS & NS & NS & NS \\
\hline & Height: $H$ & NS & NS & NS & NS \\
\hline & Daily ZNS dose: $D$ & 0.445 & NS & NS & NS \\
\hline & Hospital: $H P$ & NS & NS & NS & NS \\
\hline \multicolumn{6}{|l|}{ Simple correlation coefficient } \\
\hline $\begin{array}{l}\text { between the main-explanatory } \\
\text { variable and } C_{t}\end{array}$ & & 0.677 & 0.722 & 0.743 & 0.745 \\
\hline $\begin{array}{l}\text { Multiple correlation coefficient } \\
\text { between all selected explanatory } \\
\text { variables and } C_{\mathrm{t}}\end{array}$ & & 0.742 & 0.753 & - & - \\
\hline
\end{tabular}

NS: Not significant.

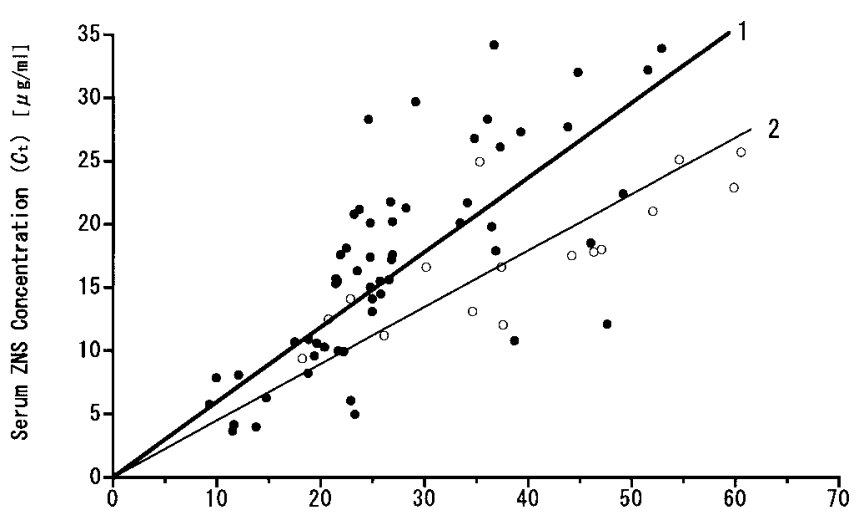

Daily ZNS Dose per Extracellular Water Volume $\left(D / V_{\text {Exx }}\right)[\mathrm{mg} /(\mathrm{I} \cdot \mathrm{d})]$

Fig. 1. Relation between Daily Dose per Extracellular Water Volume $\left(D / V_{\mathrm{ECW}}\right)$ and Serum Concentration $\left(C_{\mathrm{t}}\right)$ of ZNS

Line 1: ZNS alone; $-\bullet, C_{\mathrm{t}}=0.604 \times\left(D / V_{\mathrm{ECW}}\right)(n=57, r=0.736, p<0.01)$. Line $2: \mathrm{ZNS}+\mathrm{PHT} ;-, \bigcirc, C_{\mathrm{t}}=0.428 \times\left(D / V_{\mathrm{ECW}}\right)(n=16, r=0.745, p<0.01)$.

Table 4. $C_{\mathrm{t}} / D_{\mathrm{ECW}}^{\prime}$ Ratio and Alteration Ratio on Coadministration of One Drug

\begin{tabular}{lccc}
\hline \hline Drug coadministered & $\begin{array}{c}\text { No. of } \\
\text { patients }\end{array}$ & $\begin{array}{c}C_{\mathrm{t}} / D_{\mathrm{ECW}}^{\prime} \text { ratio } \\
\text { (mean } \pm \text { S.D.) }\end{array}$ & $\begin{array}{c}\text { Alteration } \\
\text { ratio }\end{array}$ \\
\hline- & 57 & $0.607 \pm 0.191$ & - \\
Phenobarbital (PB) & 17 & $0.578 \pm 0.220$ & $0.95 \mathrm{NS}$ \\
Varproic acid (VPA) & 32 & $0.534 \pm 0.197$ & $0.88^{\dagger}$ \\
Carbamazepine (CBZ) & 10 & $0.489 \pm 0.201$ & $0.81^{\dagger}$ \\
Phenytoin (PHP) & 16 & $0.459 \pm 0.106$ & $0.76^{* *}$ \\
\hline
\end{tabular}

$\dagger p<0.1, * * p<0.01$, NS: Not significant.

mately related to the line which intersected the origin (Fig. 1; line 2). The same results were obtained with each of the other antiepileptic drugs (data not shown). From these results (Fig. 1), the influence of the coadministered drug was evident from the change in the slope of the regression line. We could thus compared each $\mathrm{L} / \mathrm{D}$ ratio to detect the influence of another antiepileptic drug.

In Table 4, each alteration ratio is shown as the ratio of the $\mathrm{L} / \mathrm{D}$ ratio of $\mathrm{ZNS}$ plus one drug to that of $\mathrm{ZNS}$ alone. The $\mathrm{L} / \mathrm{D}$ ratio of $\mathrm{ZNS}$ alone was significantly lowered $(p<0.01)$ by PHT, and tended to be lowered $(p<0.1)$ by VPA and CBZ.

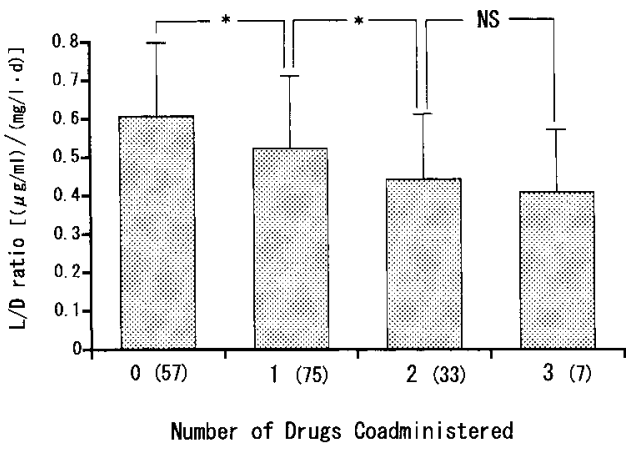

Fig. 2. Influence on L/D Ratio of Number of Antiepileptic Drugs Coadministered

Values in parentheses indicate the number of patients. $* p<0.05$, NS: Not significant.

However, PB did not have an affect.

Influence of Antiepileptic Drugs on $\boldsymbol{C}_{\mathbf{t}}$ The $\mathrm{L} / \mathrm{D}$ ratio decreased significantly $(p<0.05)$ as the number $(\leqq 2)$ of drugs coadministered increased regardless of their type. The $\mathrm{L} / \mathrm{D}$ ratio decreased with the concomitant use of 3 drugs as compared with 2 drugs (Fig. 2).

We established Eq. 4 to elevate the power of the test and to estimate the more precise influence of each drug, quantitatively.

$$
L / D_{\text {(meas) }}=L / D_{(0)} \cdot \prod_{i=1}^{6} \cdot R_{i}^{Z i}+\varepsilon
$$

where $L / D_{\text {(meas) }}$ is the measured $\mathrm{L} / \mathrm{D}$ ratio and $L / D_{(0)}$ is the $\mathrm{L} / \mathrm{D}$ ratio of $\mathrm{ZNS}$ alone. $R_{i}$ is a parameter representing the influence of each antiepileptic drug on the L/D ratio of ZNS alone. Hereafter, $R_{i}$ is called the alteration ratio. The subscript $i$ represents the drug coadministered, and $i=1$ to 6 corresponds to primidone (PMD), PB, PHT, VPA, ZNS, and clonazepam (CZP), respectively. $\varepsilon$ is an error term. $z_{i}$ is 1 or 0 when $\operatorname{drug} i$ is or is not coadministered. No regard was paid to the dose or serum concentration of the antiepileptic drugs in this model.

Multiple regression analysis revealed the drugs influencing the $\mathrm{L} / \mathrm{D}$ ratio $(p<0.05)$ and their estimated $R_{i}$ values (Table 5). PB, VPA, CBZ, and PHT were selected and would lower the $\mathrm{L} / \mathrm{D}$ ratio to $0.849,0.865,0.846$, and 0.804 of the value 
Table 5. Estimated Values

\begin{tabular}{cccc}
\hline \hline & $\begin{array}{c}\text { Drug } \\
\text { coadministered }\end{array}$ & $\begin{array}{c}\text { No. of } \\
\text { cases }\end{array}$ & $\begin{array}{c}\text { Estimated value } \\
(\text { mean } \pm \text { S.E. })\end{array}$ \\
\hline$L / D_{(0)}$ & - & 57 & $0.576 \pm 0.02[(\mu \mathrm{g} / \mathrm{ml}) /(\mathrm{mg} / \mathrm{l} \cdot \mathrm{d})]$ \\
$R_{1}$ & $\mathrm{PMD}$ & 4 & - \\
$R_{2}$ & $\mathrm{~PB}$ & 36 & $0.849 \pm 0.03^{*}\left[0.853^{*}\right]$ \\
$R_{3}$ & $\mathrm{VPA}$ & 60 & $0.865 \pm 0.03^{*}\left[0.857^{*}\right]$ \\
$R_{4}$ & $\mathrm{CBZ}$ & 32 & $0.846 \pm 0.03^{*}\left[0.853^{*}\right]$ \\
$R_{5}$ & $\mathrm{PHT}$ & 39 & $0.804 \pm 0.03^{*}\left[0.813^{*}\right]$ \\
$R_{6}$ & $\mathrm{CZP}$ & 5 & -
\end{tabular}

[ ]: Mean value calculated from $D_{\mathrm{BSA}}^{\prime} \cdot * p<0.05$.

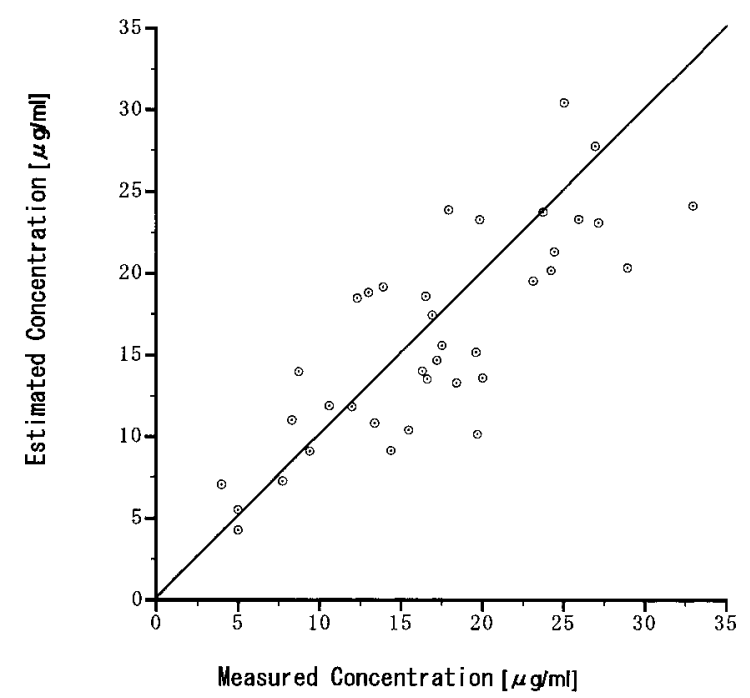

Fig. 3. Plot of Measured versus Estimated Concentrations

$\odot$ : Pairs of measured and estimated values in 37 patients. The line of identity is shown.

for ZNS alone, respectively.

Comparison of the Estimated and Measured Concentrations To evaluate each $R_{i}$ obtained in this study, measured and estimated concentrations were compared in cases where the drugs prescribed to the patient were changed. To estimate the concentration, the $\mathrm{L} / \mathrm{D}$ ratio was multiplied by $R_{i}$ when drug $i$ was added, and divided by $R_{i}$ when drug $i$ was removed. Both concentrations seem to be accurate (Fig. 3). The mean prediction error (MPE) was calculated as $22.9 \%$ from the following equation.

$$
\begin{aligned}
& \operatorname{MPE}(\%) \\
& \quad=\left\{\sum(\mid \text { measured value-estimated value } \mid / \text { measured value }) / n\right\} \times 100
\end{aligned}
$$$$
\text { ( } n \text { : number of sets compared) }
$$

\section{DISCUSSION}

The number of patients 15 years old or younger was not sufficient to detect a significant influence on the L/D ratio by the other antiepileptic drugs. Patients were allocated to two groups according to age: $A G E<15$ and $A G E \geqq 15$ (Table 2), because the relationship between the elimination rate constant and age was reported to change at $A G E=15$ for CBZ. ${ }^{12)}$ Then, the $\mathrm{L} / \mathrm{D}$ ratios of the groups were compared (Table 2).

When the transforming factors were $V_{\mathrm{ECW}}$ and $B S A$, almost the same results were obtained (Tables 2,3 ). This is ex- plained by the approximately linear relationship between $V_{\mathrm{ECW}}$ and $B S A: V_{\mathrm{ECW}}=6.04 \times B S A^{0.998} \cdot{ }^{13)} B S A$ is recommended as a transforming factor because of its close correlation with a number of age-dependent physiological parameters influencing the disposition of a drug such as renal blood flow and hepatic weight. ${ }^{14)} V_{\mathrm{ECW}}$ is also closely correlated to these parameters. Since most drugs distribute through the extracellular water space in order to reach their receptors, $V_{\mathrm{ECW}}$ is more suitable for the ultimate drug level than $B S A$. For these reasons, we selected $V_{\mathrm{ECW}}$ as a transforming factor. We suggest that $V_{\mathrm{ECW}}$ is a more suitable transforming factor for ZNS than $W$ or $V_{\mathrm{TBW}}$, and is not at all inferior to $B S A$.

A nonlinear relationship between daily dose and $C_{\mathrm{t}}$ was reported when studied intra-individually. ${ }^{15}$ ) We do not have enough data to elucidate the intra-individual relationship. However, a linear relationship for ZNS alone ${ }^{2)}$ and concomitant use of $\mathrm{ZNS}^{3)}$ was also reported. In the present study, a significant linear relationship was found between $C_{\mathrm{t}}$ and $D_{\mathrm{ECW}}^{\prime}$, and concomitant therapy changed only the slope of the regression line (Fig. 1).

PHT was found to lower the L/D ratio of ZNS $(p<0.01)$ when it alone was coadministered (Table 4). However, the number of patients coadministered one drug was not sufficient to detect the influence precisely. By elevating the power of the test and from the lowering of the L/D ratio with the increase in the number of drugs coadministered (Fig. 2), the authors postulated $R_{i}$. For Eq. 4, it was postulated that, when more than two antiepileptic drugs were coadministered, the influences of these drugs on the L/D ratio were independent from one another and multiplicative. As this model could analyze all cases inclusively, the reliability of the estimated values would be improved. As a result, PB, VPA, CBZ, and PHT were found to lower the L/D ratio significantly. As shown in Tables 4 and 5, the two L/D ratios of ZNS alone were in good agreement. The changes in Tables 4 and 5 closely corresponded to each other. These findings thus supported that the influence of each drug on the L/D ratio was independent and multiplicative.

Our results were consistent with the reports that $\mathrm{PB},{ }^{16}$ ) $\mathrm{CBZ},{ }^{17)}$ and $\mathrm{PHT}^{16)}$ lowered the $\mathrm{L} / \mathrm{D}$ ratio on concomitant use. The result $R<1$ indicates that the coadministered antiepileptic drugs mainly raise the value of the elimination rate constant. These findings would be due to the inducing effects on drug-metabolizing enzymes of these antiepileptic drugs. ${ }^{18-20)}$ Although VPA does not have this effect, it was also reported to lower the L/D ratio. ${ }^{16)}$ Thus, our results were consistent with those reported by previous investigators. It could not be clarified whether PMD and CZP had an effect or not, because of an insufficient number of patients. However, it is anticipated that PMD would lower the L/D ratio by metabolizing PB.

When evaluating each $R_{i}$ value for clinical use, the concentration of unbound ZNS in the blood should be considered. A significant increase in the free fraction of ZNS was reported following the concomitant use of VPA. The increase, however, was small and significant linear relationships were also reported between total and unbound serum concentrations of ZNS on the administration of ZNS alone and ZNS + VPA., ${ }^{2,3)}$ The clinical efficacy of ZNS would unlikely be affected by VPA. Though each $R_{i}$ was calculated from the total concentration, it sufficiently corresponds to the change in the un- 
bound concentration and is closely associated with clinical efficacy.

When the antiepileptic drugs mentioned above are changed in the same patient, the alteration of the $\mathrm{L} / \mathrm{D}$ ratio can be estimated from Eq. 4 by using the value of $R_{i}$ (Table 5). In the case where the administration of PHT is discontinued during therapy using VPA and PHT with ZNS, each L/D ratio is calculated as follows.

$$
\begin{aligned}
& L / D_{(3,5)}=L / D_{(0)} \times R_{3} \times R_{5} \\
& L / D_{(3)}=L / D_{(0)} \times R_{3}
\end{aligned}
$$

Where $L / D_{(0)}$ is the $\mathrm{L} / \mathrm{D}$ ratio of ZNS alone, $L / D_{(3,5)}$ and $L / D_{(3)}$ mean the concomitant use of VPA + PHT and of VPA, respectively.

From Eqs. 5 and 6,

$$
\begin{aligned}
\left(L / D_{(3)}\right) /\left(L / D_{(3,5)}\right) & =\left(L / D_{(0)} \times R_{3}\right) /\left(L / D_{(0)} \times R_{3} \times R_{5}\right) \\
& =1 / R_{5} \\
& =1 / 0.804 \\
& \fallingdotseq 1.25
\end{aligned}
$$

Thus, $L / D_{(3)}$ is expected to increase to 1.25 upon discontinuance of PHT. The daily ZNS dose should be reduced to 0.8 to maintain the same level of $C_{\mathrm{t}}$.

The authors calculated MPE as $26 \%$ in the same manner based on $D_{\mathrm{W}}^{\prime}{ }^{21)}$ Although the present study was a retrospective one and the clinical data were from a number of sources, we feel confident of the results (Fig. 3). As BSA was recommended as a transforming factor, the influence based on BSA was investigated in the same manner. PB, VPA, CBZ, and PHT were also selected as drugs influencing the L/D ratio. Each $R_{i}$ value (see Table 5; [ ]) and the MPE (23.0\%) was nearly equal to that calculated from $V_{\mathrm{ECW}}^{\prime}$.

Many patients switch from ZNS treatment to mono/concomitant therapy. Each alteration ratio of $R_{i}$, in our study population, could be adapted to all the patients without them being grouped by other confounding factors. This will make it easy to estimate $C_{\mathrm{t}}$ correctly on the addition or discontinuance of co-treatment with antiepileptic drugs in ZNS therapy.

\section{REFERENCES}

1) Wilensky A. J., Friel P. N., Ojemann L. M., Dodrill C. B., McCormick K. B., Levy R. H., Epilepsia, 26, 212-220 (1985).

2) Kimura M., Tanaka N., Kimura Y., Miyake K., Kitaura T., Fukuchi H., Harada Y., Chem. Pharm. Bull., 40, 193-195 (1992).

3) Ijiri Y., Ohi K., Suzuki K., Fukuoka E., Furuya T., Yoshinari S., Tamai H., Jpn. J. Hosp. Pharm., 20, 207-212 (1994).

4) Fukuoka N., Tsukamoto T., Uno J., Kimura M., Morita S., Jpn. J. Hosp. Pharm., 24, 652-660 (1998).

5) Fukuoka N., Tsukamoto T., Uno J., Kimura M., Morita S., Jpn. J. Hosp. Pharm., 26, 135-144 (2000).

6) Fukuoka N., Tsukamoto T., Uno J., Kimura M., Morita S., Jpn. J. Hosp. Pharm., 24, 642-651 (1998).

7) Fukuoka N., Tsukamoto T., Uno J., Kimura M., Morita S., Yakugaku Zasshi, 123, 35-42 (2003).

8) Ojemann L. M., Shastri R. A., Wilensky A. J., Friel P. N., Levy R. H., Mclean J. R., Buchanan A., Ther. Drug Monit., 8, 293-296 (1986).

9) Aoki S., "Tokei Program Package NAP (ver. 4.0) Manual," Igaku Shoin, Tokyo, 1995.

10) Friis-Hansen B., Pediatrics, 28, 169-181 (1961).

11) Takahira H., Report of Imperial Government Institute of Nutrition, $\mathbf{1}$, $61-95$ (1925).

12) Hori R., Okumura K., Kitazawa S., Koshiro A., Saitoh Y., Higuchi S., Mizugaki M., Yamaji A., Rikihisa T., Tanigawara Y., Yakuzaigaku, 49, 304-312 (1989).

13) Bartles H., Pediatr. Pharmacol., 3, 131-143 (1983).

14) Milsap R. L., Szefler S. J., "Applied Pharmacokinetics," 2nd ed., ed. by Evans W. E., Schentag J. J., Jusko W. J., Applied Therapeutics Inc., Spokan, 1986, pp. 294-330.

15) Wagner J. G., Sackellares J. C., Donofrio P. D., Berent S., Sakmer E., Ther. Drug Monit., 6, 277-283 (1984).

16) Shinoda M., Akita M., Hasegawa M., Hasegawa T., Nabeshima T., Biol. Pharm. Bull., 19, 1090-1092 (1996).

17) Hashimoto Y., Odani A., Tanigawara Y., Yasuhara M., Okuno T., Hori R., Biol. Pharm. Bull., 17, 323-326 (1994).

18) Riva R., Albani F., Contin M., Baruzzi A., Clin. Pharmacokinet., 31, 470-493 (1996).

19) Chiba K., Suganuma T., Ishizaki T., Iriki T., Shirai Y., Naitoh H., Hori M., J. Pediatr., 106, 653-658 (1985).

20) Sackellares J. C., Sato S., Dreifuss F. E., Penry J. K., Epilepsia, 22, 437-441 (1981).

21) Fukuoka N., Tsukamoto T., Morita S., Jpn. J. Hosp. Pharm., 23, 312 318 (1997). 